\title{
COMPORTAMENTO DO PESSEGO 'FLORDAPRINCE': NOVA SELEÇÃO BEM PRECOCE INTRODUZIDA DA FLORIDA $\left({ }^{1}\right)$
}

\begin{abstract}
MÁRIO OJIMA, FERNANDO ANTONIO CAMPO DALIORTO (2), WILSON BARBOSA (3) e ANTONIO FERNANDO CAETANO TOMBOLATO, Seção de Fruticultura de Clima Temperado, Instituto Agronômico.
\end{abstract}

\section{RESUMO}

Flordaprince (Fla. 5-2) é um novo cultivar de pêssego selecionado na Flórida, EUA, que encontrou boa adaptação nas condiçóes climáticas de inverno brando do Estado de São Paulo. Os frutos apresentam pele avermelhada bem atraente, polpa amarela e sabor doce-acidulado forte. As características de bela aparência dos frutos, baixa exigência de frio e especialmente a precocidade na maturação, motivaram a escolha deste cultivar para sua inclusão em lotes comerciais em São Paulo, como opção varietal ao 'Maravilha', e para utilização no programa de melhoramento do pessegueiro, do Instituto Agronômico.

\section{INTRODUÇÃO}

Dentro do programa de melhoramento genético do pessegueiro, a Seção de Fruticultura de Clima Temperado do Instituto Agronômico vem estudando, através de campos experimentais instalados em diferentes regiões paulistas, o comportamento de material introduzido de várias procedências. Como resultado desse trabalho, foi apresentado, em 1975 (6), o cultivar Flordabelle, selecionado na Flórida, EUA, e que, por suas qualidades de frutos graúdos, polpa firme e relativa precoci.

(1) Trabalho integrante do projeto "Desenvolvimento do cultivo de pêssegos precoces em São Paulo" do Convênio SAA(IAC)-FINEP. Recebido para publicação a 24 de junho de 1983.

(2) Com bolsa de pesquisa do CNPq.

(3) Com bolsa de aperfeiçoamento do CNPq. 
dade na maturação, é, hoje, o pêssego de mesa, de polpa amarela, mais difundido no Estado de São Paulo. Observe-se que esse tipo de pêssego não tem contado com número suficiente de cultivares em disponibilidade aos fruticultores paulistas. Para suprir essa deficiência, o Instituto Agronômico lançou, nos últimos anos, uma série de novas selecões obtidas por hibridações controladas: 'Catuíba', 'Canário', 'Ouromel-2', 'Ouromel-3', 'Ouromel-4' e 'Petisco-2' (4, 5), as quais representam, atualmente, as maiores esperanças da persicultura paulista, em termos de pêssegos amarelos e de superior qualidade para mesa. Entretanto, nem essas seleções, nem a 'Flordabelle', podem ser enquadradas no grupo dos materiais "bem precoces", cuja procura vem sendo cada vez maior.

Nessas condições, tornou-se oportuno o lançamento de uma nova seleção de pêssego de polpa amarela, que reúne as características desejáveis de produtividade, beleza dos frutos e maior precocidade de maturação, capaz de proporcionar a ampliação do período de safra, antecipando-o em até vinte dias. A apresentação do cultivar Flordaprince (Fla. 5-2) alcança esse objetivo, além de propiciar ao produtor uma opção varietal de polpa amarela ao pêssego 'Maravilha' (Fla. 13-72) (6, 9), de polpa branca e, atualmente, o material mais precoce cultivado em São Paulo.

\section{MATERIAL E MÉTODOS}

Procedentes da Universidade da Flórida, Gainesville, EUA, foram introduzidas no Instituto Agronômico, em 1979, borbulhas de vários pessegueiros selecionados como relativamente pouco exigentes de trio. Dentre essas seleções, enviadas por W. B. Sherman, melhorista daquela Universidade norte-americana, constava a indicada pela sigla Fla. 5-2, que posteriormente recebeu a designação de 'Flordaprince' (8).

Logo após a chegada do material, procedeu-se a sua enxertia sobre "seedlings" adultos de pessegueiros constantes do lote de seleção localizado no Centro Experimental de Campinas. Mantidas sob tratos culturais normais, as plantas enxertadas foram submetidas a seguidas inspeções para verificar o seu comportamento vegetativo e fitossanitário. Já no primeiro ano, 1980, elas floresceram abundantemente e proporcionaram as primeiras produçōes de pêssegos, que foram meticulosamente analisadas no campo e no laboratório; desde então, a scịção Fla. 5-2 apresentou características altamente promissoras de precocidade, tamanho, firmeza e colorido dos frutos.

Para melhor estudar o comportamento do material em outras áreas representativas de clima subtropical-temperado do Estado, instalaram-se campos experimentais nas Estações Experimentais de Jundiaí e Monte Alegre do Sul, através de novas enxertias efetuadas em 1980 e 1981. As observações estenderam-se posteriormente a lotes formados 
em locais de clima mais ameno, notadamente nas regiões de Atibaia e Paranapanema.

Os tratos culturais e fitossanitários aplicados aos lotes experimentais têm sido os normais e necessários (1), a fim de que as plantas possam reagir espontaneamente aos diferentes meios, revelando as suas reais potencialidades individuais. Exceção a esse tratamento, constitui o lote localizado em Monte Alegre do Sul : aí a seleção Fla. 5-2 está sendo estudada ao lado de 28 outras, especialmente as seleções do IAC, plantadas em ultra-alta densidade e submetidas a podas drásticas no verão. Nesse lote, adotaram-se dois espaçamentos de plantio: em renque duplo, a $3,0 \times 0,5 \times 0,5 \mathrm{~m}$, e em renque simples, a $3,0 \times 0,5 \mathrm{~m}$, que correspondem, respectivamente, a 0,875 e $1,500 \mathrm{~m}^{2}$ por planta, ou 11.428 e 6.666 plantas por hectare (2).

De todos os lotes, vêm sendo anotadas informações relativas à adaptabilidade do material, desenvolvimento vegetativo, florescimento e frutificação, bem como ao comportamento fitossanitário. As colheitas dos frutos destinados às observações pomológicas vêm sendo realizadas na época normal de maturação dos pêssegos mais precoces.

\section{RESULTADOS}

'Flordaprince' é um pêssego resultante do cruzamento entre Fla. 2-7 e 'Maravilha' (Fla. 13-72), cujos progenitores originais são 'Hawaiian' e 'Okinawa' respectivamente, dos quais provém a sua característica de baixa exigência de frio. $\mathrm{O}$ "seedling" que deu origem a esse cultivar foi selecionado em 1975, e desde então testado sob a designação de Fla. 5-2 (8).

'Flordaprince' é considerado pouco exigente de frio: somente 150 horas abaixo de $7,2^{\circ} \mathrm{C}$, fato confirmado pela excelente adaptação às condições climáticas das localidades paulistas onde foi testado. A planta apresenta boa capacidade vegetativa; desenvolvimento medianamente vigoroso; porte meio compacto; ramificação equilibrada; ramos frutíferos abundantes; boa formação de gemas, com predominância de agrupamento triplo - uma vegetativa entre duas floriferas; folhas de tamanho médio, verde-escuras e bem distribuídas. As flores são grandes, de coloração róseo-clara, autoférteis, com abundância de pólen de alta capacidade germinativa.

O florescimento pleno se processa em geral na última semana de junho, e o pegamento dos frutos é dos mais satisfatórios. A maturação dos frutos ocorre 80-85 dias após a florada, ou seja, na terceira década de setembro. Trata-se, pois, de um cultivar bastante precoce, cuja safra é coincidente com a do pêssego 'Maravilha'. 
'Flordaprince' apresenta alta produtividade; plantas de dois a três anos, em espaçamentos normais, ao redor de $7 \times 5 \mathrm{~m}$, chegaram a produzir de 20 a $30 \mathrm{~kg}$ de pêssegos, não obstante um desbaste de cerca de $50 \%$ dos frutos verdes. No ensaio de Monte Alegre do Sul, em espaçamentos de $3,0 \times 0,5 \times 0,5 \mathrm{~m}$ e 3,0 × 0,5m, foram obtidas, em 1982, produções de 2,8 e 4,8kg por planta, equivalentes a 32,2 e $30,5 \mathrm{t}$ por hectare respectivamente, na primeira frutificação de pessegueiros ainda jovens (2).

Nos lotes experimentais, não se constatou qualquer problema de natureza fitossanitária digno de registro, apresentando-se o novo cultivar com suscetibilidade moderada às principais doenças e pragas do pessegueiro incidentes em São Paulo, notadamente a ferrugem; podridão-parda, cochonilhas e ácaros (7).

O fruto é de tamanho médio, 80 a 90 gramas; forma oblongo-arredondada, praticamente sem ápice; base meio estreita, com cavidade peduncular aprofundante; sutura nítida e rasa, dividindo o fruto em duas partes assimétricas. A película, que se solta nos frutos maduros, apresenta coloração de fundo amarelada, com intensas estrias avermelhadas e aspecto muito atraente. A polpa é amarela, bonita, de boa resistência e medianamente sucosa. O caroço é de tamanho médio, alongado, meio preso à polpa, sem auréola. O sabor é regular, doce-acidulado forte, com acidez pronunciada; teor de açúcares ao redor de $11^{\circ} \mathrm{Brix}$ e acidez $\mathrm{pH} 3,7$.

\section{DISCUSSĀO E CONCLUSŌES}

'Flordaprince', com sua baixa exigência de frio, encontra adaptação das mais satisfatórias nas condiçōes subtropical-temperadas do Estado de São Paulo, revelando excelente produtividade. Destaca-se ainda pelo aspecto atraente dos frutos, de intenso colorido amarelo-avermelhado e, principalmente, pela alta precocidade de maturação, somente comparável, no momento, à do cultivar 'Maravilha', pêssego de polpa branca e caroço solto, ultimamente bastante cultivado em São Paulo, para o qual poderá constituir importante alternativa.

Considerando que a precocidade de maturação vem sendo o principal fator de sucesso econômico ao fruticultor, o novo cultivar tem perspectivas das mais favoráveis à penetração em culturas comerciais do Estado e das regiōes climatoedáficas assemelhadas. Isso possibilitará a colocação do produto no final de setembro, quando o mercado paulista ainda não dispõe de pêssegos frescos, de polpa amarela, uma vez que as boas variedades, mesmo as mais recentemente lançadas pelo Instituto Agronômico $(4,5)$, amadurecem cerca de vinte dias mais tarde. Tal expectativa é corroborada pelos resultados econômicos bastante promissores que vêm sendo obtidos com o cultivar Flordaprince em 
condições de clima análogo, em outras localidades, Tunísia $\left({ }^{4}\right)$, Ilhas Canárias (3), Israel, Austrália, México e a própria Flórida (8).

Afora a esperada contribuição que o 'Flordaprince' poderá proporcionar à fruticultura paulista: o material apresenta-se como dos mais úteis ao programa de melhoramento varietal em desenvolvimento no Instituto Agronômico. Esse cultivar tem origem em progenitores bastante diferentes daqueles inicialmente utilizados no nosso meio, resultando daí a importância em incorporar o seu potencial genético às melhores seleçōes locais de pêssegos e nectarinas.

Assim, como primeira etapa de sua utilização no programa de melhoramento do Instituto Agronômico, encontra-se hoje em formação, na Seção de Fruticultura de Clima Temperado, cerca de 200 "seedlings" procedentes dos cruzamentos controlados, efetuados em 1982, entre 'Flordaprince' e seleções IAC, envolvendo oito combinações. Para 1983, acha-se programada a realização de maior número de hibridações, a fim de aumentar a quantidade de "seedlings", que serão plantados e testados no campo, em lotes de seleção. A partir desses "seedlings", espera-se selecionar novos materiais especialmente adaptados às condições climáticas locais, e que apresentem características de precocidade, elevadas produções, frutos graúdos, de colorido intenso, firmes e de melhor palatabilidade.

\section{SUMMARY}

\section{BEHAVIOR OF 'FLORDAPRINCE', A NEW EARLY PEACH CULTIVAR INTRODUCED FROM FLORIDA}

Flordaprince (Fla . 5-2) is a new early red skin yellow fleshed peach cultivar selected at the Florida Agricultural Experiment Station for its adaptation to the mild winter of central Florida, U.S.A. It was introduced in 1979 in the State or São Paulo, Brazil, where its behavior in the local climatic conditions has been observed. The low chilling requirement (about 150 hours below $7.2^{\circ} \mathrm{C}$ ), high tree vigor and productiveness, beautiful appearance and early ripening of fruits are characteristics that justify its inclusion in the commercial plots in São Paulo and in the peach breeding program of the Instituto Agronômico.

\section{REFERENCIAS BIBI.IOGRAFICAS}

1. CAMPINAS. Instituto Agronômico. Instruções agricolas para o Estado de São Paulo. 2.ed. rev. atual. Campinas, 1980. 273p. (Boletim, 200')

2. CAMPO DALLORTO, F. A.; OJIMA, M.; BARBOSA, W.; TOMBOLATO, A. F. C.: RIGITANO, O.; ALVES, S. Cultivo de seleçōes de pessegueiros precoces no sistema de pomar compacto com poda drástica de renovação da copa. Pesquisa Agropecuária Brasileira, Brasília, 19(6):719-727, 1984.

(4) TOMBOLATO, A. F. C. Relotório de viagens técnicas - Tunisia, INRA, "La Grande Ferrade", França, 1982. 15p. (Não publicado) 
3. CARDONA BELLVER, A. Melocotoneros para las Islas Canárias. Madrid. Ministério de Agricultura, 1981. 23p. (Hojas Divulgadoras, 8/81)

4. OJIMA, M.; CAMPO DALL'ORTO, F. A.; RIGITANO, O.; SCARANARI, H. J. MARTINS, F. P.; TOMBOLATO, A. F. C.; BARBOSA, W. Quatro novos cultivares IAC de pêssegos amarelos para mesa. Bragantia, Campinas 42:271-279, 1983.

5. - RIGITANO, O; CAMPO DALLORTO, F. A.; SCARANARI, H. J.; MARTINS, F. P.; TOMBOLATO, A. F. C. Catuíba e Canário: novos cultivares de pêssegos amarelos para mesa. Campinas, Instituto Agronômico, 1982. 10p. (Boletim técnico, 73)

6. Rigitano, O.; OJIMA, M.; CAMPO DALL'ORTO, F. A. Comportamento de novas seleções de pêssegos introduzidos da Flórida. Campinas, Instituto Agronômico, 1975. 12p. (Circular, 46)

7. SĀO PAULO. Secretaria de Agricultura e Abastecimento. Programa paulista de fruticultura de clima temperado - PRO-FRUTI. São Paulo, 1983. 96p.

8. SHERMAN, W. B.; LYRENE, P. M.; MORTENSEN, J. A.; SHARPE, R. H. Flordaprince, a peach for Central Florida. Gainesville, University of Florida, 1982. 4p. (Circular, S-294)

9. — - SOULE, J.; ANDREWS, C. P. Distribution of Florida peaches and nectarines in the tropics and subtropics. Gainesville, University of Florida 1978. 3p. (Journal series, 665) 